\title{
The Sleep Solution
}

\section{Preeti Devnani ${ }^{1,2}$}

Published online: 1 February 2018

(c) Springer Nature Singapore Pte Ltd. 2018

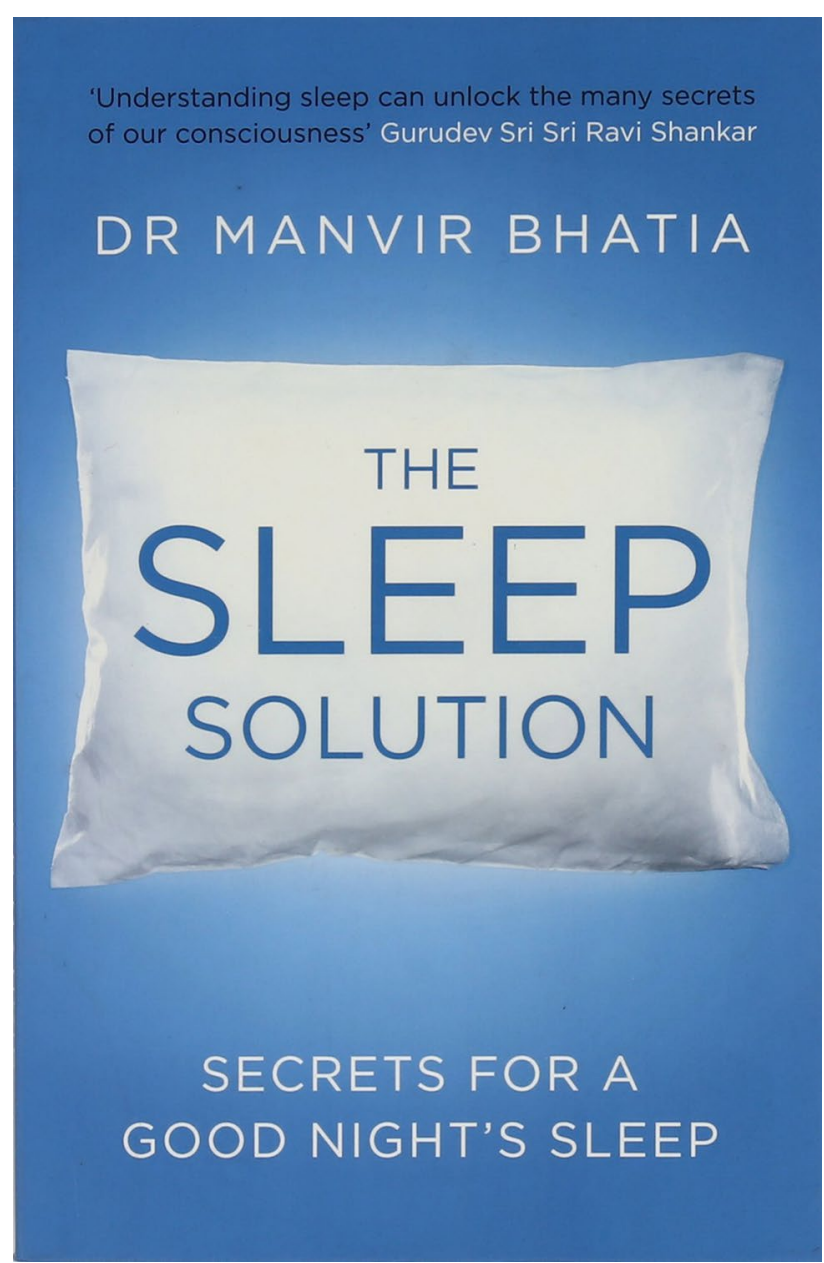

Society today is plagued with sleep complaints ranging from minimal to chronic. We tend to accept such long-standing sleep issues that impair our quality of life. Queries such as 'What is a Sleep Disorder?', 'Why do I have this sleep problem?', and more pertinently 'How to tackle these issues?' keeps the internet abuzz. The availability of a credible referral guide that can simplistically attempt to fill this lacuna is the need of the hour. Dr. Manvir Bhatia, a stalwart in the field of Sleep Medicine, with decades of experience in the sleep field has put forth this book to address these much needed issues. This concise, forthright and all-inclusive guide highlights the multidimensional role of sleep and can benefit the general public, patients, caregivers as well as the medical fraternity.

The book is subdivided into four sections: Understanding Sleep, Sleep and the Body, Sleep Problems and Sleep Solutions. The importance of sleep and consequences of sleep deprivation on neurocognitive, metabolic, cardiovascular functions are highlighted. The common sleep ailment section candidly addresses frequently asked questions and describes polysomnography-sleep testing and other assessments, decoding these complex diagnostic tests and reassuring the readers. Case studies are strategically used to highlight common ailments and scientifically explain the strategy in solving them. The section on technology is very relevant in our current scenario, new innovations are revolutionizing sleep analysis yet on the flipside they are one of the major contributors to our new age sleep issues. The tabulations that follow every section help crystallize the core features and essential take-home points.

I highly recommend this comprehensive and relevant guide to sleep that serves as a benchmark in conveying pertinent scientific information in an easy to read format. It can serve as a reference guide across the ages for people from all walks of life.

Preeti Devnani

drdevnani@gmail.com

1 Cleveland Clinic, Abu Dhabi, United Arab Emirates

2 Sleep Disorders Clinic, Mumbai, India 